\title{
A TWO-YEAR REVIEW OF UTERINE RUPTURE IN A REGIONAL HOSPITAL
}

\author{
C.O. FOFIE and P. BAFFOE \\ Ghana Health Service, Regional Hospital, Wa, Upper West Region, Ghana.
}

Corresponding Author: Dr. Chris Opoku Fofie

Email:fofiy2000@yahoo.com

Conflict of Interest: None declared

\begin{abstract}
SUMMARY
Background: Uterine rupture causes high maternal and neonatal mortality in many rural setting in the world. Further studies might provide specific interventions to reduce the high prevalence.

Objective: To determine the frequency, causes, clinical presentation, management and outcome of uterine rupture
\end{abstract}

Setting: Department of Obstetrics and Gynaecology, Upper West Regional Hospital, Wa, Ghana.

Design: Retrospective descriptive study.

Method: A descriptive study of cases of ruptured uterus in the Regional Hospital from 1st January, 2007 to 31 st December 2008 was done. A structured questionnaire was developed to collate data from various registers for analysis.

Results: Total deliveries were 5085 with $4172(82 \%)$ spontaneous vaginal delivery and 911(17.9\%) caesarean sections. Uterine rupture occurred in 41 cases for a ratio of 1:124 Grand multipara with five or more deliveries represented $41.5 \%$ while those with two prior successful deliveries represented $31.7 \%$. The mean parity was 3.8 (SD 2.3) under antenatal care, $85.4 \%$ had at least four visits. Severe anaemia $28(68.3 \%)$ and abdominal tenderness $27(65.8 \%)$ were the most frequent clinical presentation while the use of local herbal concoction with suspected uterotonic activity $24(58.5 \%)$, fetopelvic disproportion $4(9.8 \%)$ and malpresentation $5(12.1 \%)$ were the most significant causes. Major complications were: neonatal deaths 34(82.9\%), maternal mortality 4(9.8\%) and wound infections $15(36.6 \%)$. Subtotal hysterectomy $10(24.4 \%)$ and total hysterectomy $18(43.8 \%)$ were preferred to uterine repair $12(23.3 \%)$ and $87.8 \%$ required at least two units of blood transfusion. Conclusion: skilled attendance with accessible emergency obstetric care and focused antenatal care are key elements for the prevention and management of uterine rupture.

\section{INTRODUCTION}

Since time immemorial, indigenous people in Africa and other parts of the world have relied on prayers, rituals and sacrifices to gods to control obstetric accidents and maternal mortality. Attempts to imitate the success story of western countries in lowering maternal mortality drastically have failed in Africa because the poor majority still do not have access to the basic life saving techniques, hence the persistent unacceptably high maternal mortality ratio. In 2005, an estimated 536,000 women died from causes related to childbirth in the world and $95 \%$ were from Africa and Asia. ${ }^{1}$ Ghana, similar to many sub-Saharan countries is still burdened with a maternal mortality ratio between 214 and 820 per 100000 live births ${ }^{2}$, mostly from preventable causes. No single monument has been erected on our landscape in memory of these numerous victims yet almost all adult Ghanaians have had relatives or friends being direct victims.

Uterine rupture stands as a single obstetric accident that exposes the flaws and inequities of health systems and the society at large due to the degree of neglect that it entails. Again, it has the unique potential to impact negatively on Millennium Development Goals 4 and 5. Uterine rupture is a potentially catastrophic event during childbirth in which the integrity of the myometrial wall is breached. ${ }^{3}$ In a complete rupture there is full-thickness separation of the uterine wall with the expulsion of the foetus and/or placenta into the abdominal cavity where-as the overlying serosa or peritoneum is spared in an incomplete rupture. ${ }^{3,4}$ This obstetric accident is closely associated with maternal and/or foetal mortality and morbidity such as bladder rupture, vesicovaginal and rectovaginal fistula, foot drop and psychological trauma.

Trial of labour on scarred uterus and the use of uterotonics during labour are the most frequent causes in the developed world while neglected and obstructed labour ${ }^{5}$ stand as the principal factors in developing countries where multi parity and the use of local concoction with suspected uterotonic activity serve as aggravating factors. Despite the increasing public concern and support, the most vulnerable: the poor illiterate women from rural communities and their babies hardly get the needed attention. 
Lack of financial and human resources in remote areas pave the way for unskilled delivery, obstructed labour and subsequently uterine rupture. Those who manage to survive the acute haemorrhage might not do so with infection related complications. The occurrence of obstetric fistula and psychological trauma mark the end of a happy womanhood and the very beginning of seclusion and desolation in a victim's life. Considering the suffering and agony pregnant women go through, it is an indictment on society if proactive interventions are not put in place to make pregnancy and delivery safe. It is against this background that we conducted this study to review the cases of ruptured uterus in the Upper West Regional Hospital from 1st January 2007 to $31^{\text {st }}$ December 2008 with the objective of determining its frequency, causes, clinical presentation and outcome to improve prevention and management.

\section{METHOD}

The Upper West Regional Hospital is located in the centre of the capital, Wa. It serves as a Regional and District Hospital and also as a referral centre for SawlaTuna-Kalba and Bole Districts in the Northern Region. It has a total bed capacity of 189 with 37 for obstetrics and gynaecology. A retrospective study of all cases of ruptured uterus in the Regional Hospital from January 1st 2007 to December 31 2008 was done where a questionnaire was developed to collect data from delivery registry, patients' folders, theatre registry and admission/discharge registry. The relevant data collected included age, parity, district, clinical presentation, operation findings, maternal/foetal outcome, complications and management. The data was entered and analyzed with SPSS 11.5 for Windows.

\section{RESULTS}

In the specified period under study, a total of 5085 deliveries were conducted in the Regional Hospital with 4174 spontaneous vaginal deliveries (82\%) and 911 caesarean sections $(17.9 \%)$. A total of 41 uterine ruptures were recorded making an incidence of 1:124.The ages of clients ranged between 18 and 45 years with a mean of 31.1(SD 7.1) years. As many as $26(63.4 \%)$ patients were between 30 and 45 years. Fourteen $(41.5 \%)$ were grand multipara, (women with five or more previous deliveries) while $13(31.7 \%)$ had had two prior successful deliveries. The mean parity was 3.8(SD 2.3).On antenatal attendance, only 6 clients (14.6\%) were non-attendants and therefore did not have antenatal card. The remaining 35 clients $(85.4 \%)$ had antenatal cards and visited a health facility at least four times during the pregnancy.
On the other hand $20(80 \%)$ were not registered with the National Health Insurance Scheme (NHIS). A few clients had a previous caesarean section or a previous surgery on the uterus $7(17.1 \%)$. The majority, $34(82.9 \%)$ had never had any surgery on the uterus. The ain clinical features on presentation are shown in Table 1 .

Table 1: Clinical Presentation of Patients with Uterine Rupture

\begin{tabular}{|l|c|c|}
\hline Clinical Presentation & No. & Percentage (\%) \\
\hline Severe Anaemia & 28 & 68.3 \\
\hline Abdominal Tenderness & 27 & 65.8 \\
\hline Vaginal Bleeding & 18 & 43.9 \\
\hline $\begin{array}{l}\text { Foetal Parts Freely } \\
\text { Palpable }\end{array}$ & 26 & 63.4 \\
\hline Signs Of Infection & 12 & 29.3 \\
\hline Shock & 14 & 34.1 \\
\hline
\end{tabular}

Intra operatively, 33 clients $(80.5 \%)$ had complete rupture with babies extruded from the uterus as against $8(19.5 \%)$ incomplete ruptures with babies still in the uterus. With the exception of one client who died during the initial resuscitation, all the others had successful surgical interventions. Uterine repair was performed for $12(23.3 \%)$ clients while $10(24.4 \%)$ had subtotal hysterectomy and $18(43.8 \%)$ had total hysterectomy. Though the aetiology was noted to be multifactorial, Table 2 shows the various associated factors.

Table 2: Causes Of Uterine Rupture

\begin{tabular}{|l|c|c|}
\hline CAUSES & No. & $(\%)$ \\
\hline Herbal Concoctions & 24 & 58.5 \\
Previous Caeserean Section & 6 & 14.6 \\
Foeto-pelvic Disproportion & 5 & 12.1 \\
Oxytocin & 4 & 9.8 \\
\hline
\end{tabular}

Only $5(12.2 \%)$ did not receive blood transfusion as part of their intra operative or postoperative management. The remaining $36(87.8 \%)$ were transfused at least two units of blood. The impact of uterine rupture is said to be great due to the high complication burden involved. The neonatal deaths were $34(82.9 \%)$ for a neonatal case fatality rate of $82 \%$, maternal mortality $4(9.8 \%)$, wound infections $15(36.6 \%)$, septicaemia 8(19.5\%), bladder rupture $3(7.3 \%)$ and vesico-vaginal fistula $2(4.9 \%)$ 


\section{DISCUSSION}

For a total of 5085 deliveries, 41 cases of uterine rupture making an incidence of 1:124 is on the high side. Gardeil et al in a study from Ireland showed that the rate of unscarred uterine rupture during pregnancy was 1 per 30,764 deliveries $(0.0033 \%){ }^{6}$ A metaanalysis of data from industrialized countries suggests that the modern rate of unscarred uterine rupture during pregnancy is $0.013 \%$ ( 1 in 7440). In developing countries however an incidence of $0.11 \%$ ( 1 of 920) has been recorded. Adanu et al report1:425 from the Korle-Bu Teaching Hospital in Ghana. ${ }^{7}$ The difference between the frequencies in $\mathrm{Wa}$ and Korle-Bu simply illustrates the socio-economic dichotomy even within the same country.

The frequency of uterine rupture increases with maternal age. As many as $63.4 \%$ of clients with uterine rupture were between 31 and 45 years of age. Similar work was presented by Shipp et al who had $1.4 \%$ of uterine rupture in women older than 30years as against $0.5 \%$ in younger women. ${ }^{8}$ Multiparity has long been associated with uterine rupture. A mean parity of 3.8 (SD 2.3) with $41 \%$ of cases being grand multipara is similar to the findings of Schrinsky and Benson who found $32 \%$ of unscarred uterine rupture in women with parity greater than four. ${ }^{9}$ However, Gardeil et al found only $2(0.005 \%)$ women with uterine rupture among 39,529 multigravidas who had no previous uterine scar. ${ }^{6}$ That can be explained by the society in which he conducted his study, the socioeconomic status and the development of their health system. Only $16 \%$ of clients were non-attendants at antenatal clinic. The remaining $85.4 \%$ had at least four antenatal visits as recommended by the World Health Organization yet, they faced one of the worst preventable obstetric complications. The need to adopt focused antenatal care and upgrade the quality of care at the clinics cannot be over emphasised. The low patronage of the National health insurance scheme (20\%) raises concerns about financial barrier as a contributing factor to the delay in accessing health care. The free delivery package introduced by the Government of Ghana in 2008, attempts at addressing the issue of financial barrier but the high cost of transportation and the poor state of our roads really reduces significantly the effectiveness of this intervention in many remote areas.

Unlike in developed countries where foetal heart rate abnormalities are the first identified manifestations of uterine rupture ${ }^{10}$, late signs like abdominal tenderness $(65.8 \%)$, severe anaemia $(68.3 \%)$ and vaginal bleeding $(43.9 \%)$ are the most common ones here. Severe anaemia presenting in $68 \%$ of cases is consistent with the $60 \%$ reported by Cowan ${ }^{11}$ but in sharp contrast with the $25 \%$ from Shipp et al. The fact that Shipp's cases were for trial of labour after caesarean section could explain the comparative lower percentage of anaemia. As high as $87.8 \%$ of women with uterine rupture in our study required blood transfusion. That is probably due to the poor haemodynamic state in which our clients arrived and the high prevalence of anaemia in pregnancy.

In a Study by Kieser and Baskett, $44 \%$ of cases required blood transfusion, ${ }^{12}$ whereas Leung et al report a much less number of cases $(29 \%)$ requiring blood transfusion. ${ }^{13}$ Hysterectomy was performed in $68.2 \%$ of cases $(24.4 \%$ subtotal and $43.8 \%$ total) as against $23.3 \%$ uterine repair. Murta et al found no significant difference in terms of outcome between total and subtotal hysterectomy. ${ }^{14}$ Repair is an option for younger clients with simple transverse rupture without signs of infection but in multiparous clients arriving late with overt signs of infection, hysterectomy might be yet a better option. In the absence of a skilled person to perform hysterectomy, repair might be safer. Admassu from Debre Markos Hospital in Ethiopia reports $81 \%$ of hysterectomy as against $19 \%$ repairs. $^{15}$ In a South African study, $78 \%$ of the cases had hysterectomy ${ }^{16}$ while Flamm et al report only $8 \%$ of cases requiring hysterectomy. ${ }^{17} \mathrm{~A}$ variant of local herbal concoction (called ' kalguteem" or "MASUGE" in local parlance) suspected to have uterotonic activity was used by 24 clients $(58.5 \%)$ to hasten labour.

Oxytocin and misoprostol were used on $2.4 \%$ of clients each respectively. Contrary to references from the western world where oxytocin and prostaglandins are seriously implicated in the genesis of uterine rupture, ${ }^{18}$ the situation is quite different here. This herbal concoction with suspected uterotonic activity has been used by the indigenous people in the three Northern Regions of Ghana for several centuries to hasten labour. Precipitate labour induced by this concoction is well appreciated by the locals and therefore a great incentive to continue its use. However, in the midst of a degree of feto-pelvic disproportion, foetal distress and uterine rupture may ensue. Perinatal fatality of $82 \%$ is slightly higher than reports by Adanu (74.3\%) and Elkady $(73.1 \%)^{19}$ and lower than that of Sameera $(91.2 \%)$ from Pakistan ${ }^{20}$ Maternal case fatality of $9.8 \%$ is consistent with the $5-10 \%$ reported by Mokgokong from South Africa ${ }^{16}$ and contrasting with the $1 \%$ by Adanu from the Korle-Bu Teaching Hospital in Ghana. On the other hand, Kwame Aryee et al from the same Hospital looked at peripartum hysterectomy where ruptured uterus was cited as indication for hysterectomy in $89(48.9 \%)$ cases out of which $6(27.3 \%$ ) died making a case fatality of $6.7 \% .^{21}$ Golan and Elkady reported $15 \%$ and $21.4 \%$ respectively in their 
review. ${ }^{19,22}$ Bladder injury of $(7 \%)$ is much lower than the $18.5 \%$ reported by Gessessew from Ethiopia. ${ }^{23}$

In a comparative analysis of the statistics for the years 2007 and 2008, though total deliveries increased by $22.3 \%$, caesarean sections increased as well by $28.3 \%$. Uterine rupture incidence dropped from 1:91 to 1:174 where as uterine rupture related maternal mortality dropped from $16 \%$ to zero and perinatal mortality decreased by $45.4 \%$. Good antenatal care, access to skilled delivery and emergency obstetric care are key elements to reduce uterine rupture and its associated complications. The antenatal care coverage in the country is quite acceptable $(96 \%$ in Ghana Maternal Health Survey 2007); though the quality of care offered will definitely need to be upgraded.

Poor knowledge of pregnant women about danger signs, poor road network and inadequate skilled attendants in the health facilities are some of the contributing factors to the delay. Emergency community transport systems, equitable distribution of health staff and the creation of maternity waiting homes could help address the problem. Availability of blood banks with sustainable blood supply is indispensable. The use of herbal concoctions to hasten labour should be looked at carefully. Perhaps a scientific research to determine the properties of the active ingredient will help put it into proper use in obstetrics.

\section{ACKNOWLEDGEMENT}

We are grateful to Dr J.C.B Dakubo and Dr Mirtha Johnson for their guidance. To Dr Sylvia Deganus, we really appreciate her immense encouragement.

\section{REFERENCES}

1. United Nations Children's Fund. The State of the World's Children 2009. New York: UNICEF; 2009. 22-3.

2. Ministry of Health. The Ghana Health Sector Annual programme of Work 2004. Accra: Ministry of Health; 2004.

3. Cunningham FG, Gant NF, Leveno KJ, et al. Rupture of the uterus In: Williams obstetrics.21st ed. New York, NY: McGraw-Hill; 2001.646-52p.

4. Plauche W, VonAlmen W, Muller R. Catastrophic uterine rupture. Obstet Gynecol. 1984; 64:792-3.

5. Iloki LH, Okongo D, Ekoundzola JR. Uterine rupture in an African environment. J Gynecol Obstet Biol Reprod. 1994; 23(8): 922-5.

6. Gardeil F, Daly S, Turner MJ. Uterine rupture in pregnancy reviewed. Eur J Obstet Gynecol Reprod Biol.1994; 56(2):107 -10
7. Adanu RMK, Obed SA. Ruptured uterus: A seven-year review of cases from Accra, Ghana. $J$ Obstet Gynaecol Can. 2003; 25(3): 225-230.

8. Shipp TD, Zelop C, Repke JT, et al. The association of maternal age and symptomatic uterine rupture during a trial of labor after prior cesarean delivery. Obstet Gynecol.2002; 99(4):585 -8.

9. Schrinsky DC, Benson RC. Rupture of the pregnant uterus: a review. Obstet Gynecol Surv. 1978; 33(4):217 -32.

10. Bujold E, Gauthier RJ. Neonatal morbidity associated with uterine rupture: what are the risk factors? Am J Obstet Gynecol. 2002; 186(2):311 4.

11. Cowan RK, Kinch RA, Ellis B, Anderson R. Trial of labour following cesarean delivery. Obstet Gynecol. 1994; 83(6):933 -6.

12. Kieser KE, Baskett TF. A 10-year populationbased study of uterine rupture. Obstet Gynecol. 2002; 100(4):749 -53.

13. Leung AS, Leung EK, Paul RH. Uterine rupture after previous cesarean delivery: maternal and fetal consequences. Am J Obstet Gynecol. 1993; 169(4):945-50.

14. Murta FF, Carniero JG, De Frectas MM. Total hysterectomy versus subtotal hysterectomy: which procedure should be done during the pregnantpuerperal period? Rev Perinat Med.1993; 111: 354.

15. Admassu A, Analysis of Ruptured Uterus in Debre Markos Hospital, Ethiopia. East Afri Med J.2004; 81(1):52-5.

16. Mokgokong ET, Marivate M. Treatment of the ruptured uterus. S Afr Med J. 1976; 50:162

17. Flamm BL, Goings JR, Liu Y, Wolde-Tsadik G. Elective repeat cesarean delivery versus trial of labour: a prospective multicenter study. Obstet Gynecol. 1994; 83(6):927 -32.

18. Saglamtas M, Vicdan K, Yalcin H, Yilmaz Z. Rupture of the uterus. Int $\mathrm{J}$ Gynaecol Obstet. 1995; 49(1):9-15.

19. Elkady AA, Bayomy HM, Bekhiet MT, Nagib HS, Wahba AK. A review of 126 cases of ruptured gravid uterus. Int Surg. 1993; 78(3):2315

20. Sameera Khan, Zahida Parveen, Shamshad Begum, Iqbal Alam.Uterine Rupture: A review of 34 cases at Ayub Teaching Hospital Abbottabad. J Ayub Med Coll Abottabad.2003; 15(4):50-2.

21. Kwame-Aryee R, Kwakye A, Seffah J. Peripartum Hysterectomies at the Korle-Bu Teaching Hospital: A Review of 182 Consecutive Cases. Ghana Med J. 2007; 41(3):133-8. 
22. Golan A, Sandbank O, Rubin A. Rupture of the pregnant uterus. Obstet Gynecol. 1980; 56(5):549 -54.

23. Gessessew A, Melese MM. Ruptured uterus: eight year retrospective analysis causes and management outcome in Adigrat Hospital, Tigray Region, Ethiopia. Ethiop J Health Dev. 2002; 16(3):241-5. 